\title{
RANCANGAN PENYUSUNAN LAPORAN KEUANGAN BERBASIS MICROSOFT ACCES BERDASARKAN SAK EMKM PADA UKM DEWI PROL TAPE
}

\author{
Fitroh Marga Mila Aria Admaja, \\ Ulfi Kartika Oktaviana, SE., M.Ec., Ak., CA \\ Jurusan Akuntansi Fakultas Ekonomi \\ Universitas Islam Negeri Maulana Malik Ibrahim Malang \\ ariaadmaja23@gmail.com, ulfiko@yahoo.com
}

\begin{abstract}
Dewi prol tape is one of Micro Small and Medium Entities which already have Micro Small Business Permit (IUMK) and turnover which increase every year. With administrative completeness as well as a good turnover increase, in the preparation of its financial statementsare still not compiled well and in accordance with SAK EMKM. The preparation of the required financial statements is software-based for easy use by the UKM. Software used is microsoft acces where in operation does not require high accounting skills and does not require the cost to get it. So with that background this research is done with the title: "Design of Preparation of Financial Statements Based in Microsoft Access Based on Financial Accounting Standards of Small and Medium Entities (SAK EMKM) at UKM Dewi Prol Tape".

This research used qualitative method with case study approach. The location of the research is UKM Dewi Prol Tape located on Danau Paniai street 2 c7 e5 Sawojajar, Madyopuro, Kedungkandang, Malang City. The subject of research is the owner of UKM Dewi Prol Tape. The data was collected by triangulation method. Data analysis methods that used consist of: data collection, data reduction, data presentation and conclusion.

The result of the research shows that the design of preparation of financial statements based in Microsoft accessbased on Financial Accounting Standards of Small and Medium Entities (SAK EMKM) for UKM Dewi Prol Tape is: report of cost of goods manufactured, income statement, statement of financial position and notes to financial statement. And the obstacles that faced in the presentation of financial statements are: a) lack of human resources in preparing financial statements, b) lack of knowledge of Financial Accounting Standards of Small and Medium Entities(SAK EMKM).
\end{abstract}

Keywords : Design of Preparation, Financial Statement, Financial Accounting Standards of Small and Medium Entities (SAK EMKM)

\section{PENDAHULUAN}

Dewi Prol Tape adalah salah satu Usaha Mikro Kecil Menengah yang ada di Kota Malang, yang sudah secara resmi memiliki Ijin Usaha Mikro Kecil (IUMK). UKM ini berdiri pada tahun 2016, akan tetapi dalam kurun waktu 2 tahun dapat dilihat perkembanganya melalui peningkatan omzet penjualannya sebesar 30\%-50\%. Dengan kelengkapan admisnistrasi serta peningkatan omzet penjualan yang sedemikian bagusnya dalam pengelolaan keuangan UMKM ini belum melakukan proses akuntansi, sehingga dalam pengaturan keuanganya masih terbilang kurang, sehingga perlu adanya perancangan penyusunan laporan keuangan guna mengembangkan UKM Dewi Prol Tape.

Perlu adanya inovasi dalam perancangan penyusunan laporan keuangan yang mudah dan bisa dilakukan dengan tanpa menyita waktu yang banyak, agar permasalahan 
yang terjadi dapat diatasi. Salah satu solusi yang sangat tepat adalah rancangan penyusunan laporan keuangan yang tidak manual yang bersifat otomatis atau berbasis software, perangkat lunak/software merupakan salah satu faktor kunci untuk inovasi teknologi (Primus, 2015). Dengan adanya software akan lebih mempermudah pemilik UMKM atau yang kurang mengerti akan akuntansi, dalam menyusun laporan keuangan serta tidak memerlukan waktu yang lama. Perhitungan yang dilakukan pun juga lebih menunjukkan hasil yang akurat serta penyimpanan data lebih aman, Sehingga perlu adanya basis software dalam perancangan ini.

Usaha Mikro, Kecil, dan Menengah atau disingkat UMKM, merupakan salah satu tiang perekonomian negara. Menurut data yang diperoleh dari Kementrian Koperasi dan UMKM, pada tahun 2017 diperkirakan jumlah UMKM berkembang sekitar 59.000 .000 unit (http://www.depkop.go.id/). Oleh karena andil yang cukup besar dari UMKM kepada negara, pemerintah pun juga memberikan dukungan yang besar dalam pengembangan UMKM melalui media pembiayaan, "Pembiayaan UMKM di Indonesia sumbernya adalah melalui lembaga perbankan dan lembaga keuangan bukan bank seperti: pegadaian, modal ventura dan pasar modal" (CFISEL dkk., 2009). Dengan segala kemudahan pembiayaan yang telah disediakan, tercatat jumlah rekening kredit UMKM sebesar 14,7 juta pada tahun 2016. Jumlah yang sangat kecil apabila dibandingkan dengan total UMKM yang jumlahnya 59 juta unit, berarti hanya 24,9\% UMKM yang mengakses pembiayaan kepada lembaga keuangan perbankan (Departemen Pengembangan UMKM-Bank Indonesia, 2016). Hal ini disebabkan para pelaku UMKM belum mampu memenuhi semua persyaratan yang diajukan oleh perbankan, yang salah satunya adalah menyertakan laporan keuangan.

Pentingnya laporan keuangan bagi para pelaku UMKM sudah tidak bisa diragukan lagi, Audriene (2017) menyatakan, Otoritas Jasa Keuangan atau OJK mempunyai target dalam waktu lima tahun mendatang, 1.500 Perusahaan Usaha Mikro, Kecil dan Menengah melakukan penawaran umum saham perdana atau bisa disebut IPO (Initial Public Offering). Dimana komponen terpenting dalam proses IPO adalah penyajian laporan keuangan yang sesuai dengan standar. Hal ini tentu juga akan menjadi motivasi bagi para pelaku UMKM agar dapat menyajikan laporan keuangan yang sesuai standar dan dapat mengikuti target OJK di lima tahun mendatang.

Dewan Standar Akuntansi Keuangan Ikatan Akuntansi Indonesia (DSAK IAI) merespon dengan baik akan kebutuhan UMKM terhadap penyajian laporan keuangan, dengan menerbitkan SAK ETAP pada tahun 2009. Seiring berjalannya waktu dan kebutuhan terhadap standar yang lebih sederhana, DSAK IAI pada tahun 2016 menerbitkan standar 
baru yang khusus untuk para pelaku UMKM yang disebut dengan SAK EMKM yang diberlakukan aktif per 1 Januari 2018. Penelitian ini bertujuan untuk membuat rancangan penyusunan laporan keuangan berbasis Microsoft acces berdasarkan SAK EMKM Pada UKM Dewi Prol Tape.

\section{TINJAUAN PUSTAKA}

UMKM

Menurut Raja dkk., (2010) UMKM adalah singkatan dari Usaha Mikro Kecil dan Menengah yang seringkali dihubungkan dengan jumlah kepemilikan modal yang terbatas dalam melakukan usaha oleh seseorang atau sekelompok orang.

\section{SAK EMKM}

Standar Akuntansi Keuangan Entitas Mikro, Kecil, dan Menengah (SAK EMKM) Per 2018 menyatakan bahwa SAK ETAP karena mengatur transaksi yang sering dilakukan oleh UMKM dengan dasar pengukuran adalah biaya historis. SAK EMKM ini juga dilengkapi dengan hal-hal yang bukan merupakan bagian dari SAK EMKM, yakni dasar kesimpulan (DK) dan contoh ilustratif. Dasar kesimpulan memberikan penjelasan atas latar belakang pengaturan akuntansi yang diterapkan dalam SAK EMKM ini. Contoh ilustratif memberikan contoh-contoh penerapan SAK EMKM sehingga dapat memudahkan EMKM dalam menerapkan SAK ini.

1. Microsoft Acces

Pengertian mengenai Microsoft acces menurut Sadeli (2011), adalah sebagai berikut:

"Microsoft acces merupakan suatu perangkat lunak yang dapat digunakan untuk mengolah database yang bersifat RDBMS (relational database management system). Acces akan menyusun informasi yang banyak secara sistematis dan disimpan ke dalam komputer dalam bentuk tabel pada sebuah database."

\section{METODE PENELITIAN}

Penelitian ini menggunakan jenis penelitian kualitatif dengan pendekatan studi kasus. Lokasi penelitian adalah pada UKM Dewi Prol Tape yang beralamat di Jalan Danau Paniai Dalam 2 c7 e5 Sawojajar, Madyopuro, Kedungkandang, Kota Malang, Jawa Timur 65138. Subyek penelitiannya adalah pemilik UKM Dewi Prol Tape dengan sumber data yang digunakan adalah data primer yang berupa hasil wawancara dan observasi serta data sekunder yang berupa catatan transaksi keuangan UKM. Teknik pengumpulan data 
menggunakan metode triangulasi dengan metode analisis data yang digunakan terdiri dari: pengumpulan data, reduksi data, penyajian data dan kesimpulan.

\section{HASIL DAN PEMBAHASAN}

Dewi Prol Tape merupakan UKM yang berbentuk manufaktur, dimana aktivitas utamanya adalah memproduksi prol tape dan prol tape cracker. Transaksi-transaksi yang terjadi pada UKM Dewi Prol Tape disampaikan oleh Mbak Dewi selaku pemilik UKM dalam wawancara yang dilakukan pada hari Kamis 26 April 2018 Pukul 10:22 WIB di Kediamannya:

"Karena produkku Prol Tape jadi ya disini kita membeli bahan baku pertama, terus setelah itu kita produksi mas dengan tiga karyawan yang juga termasuk saya, dan setelah produksinya selesai lalu kita jual produknya."

Dari penuturan tersebut dapat diketahu bahwa transaksi yang terjadi pada UKM Dewi Prol Tape adalah pembelian bahan baku, produksi dan penjualan. Dimana metode pencatatan yang digunakan adalah metode perpetual. Sehingga dari transaksi pembelian bahan baku akan muncul akun persediaan bahan baku, dan dari proses produksi akan muncul persediaan bahan dalam proses yang dihasilkan dari biaya bahan baku, biaya tenaga kerja langsung dan biaya overhead pabrik dan persediaan barang jadi, serta dari transaksi penjualan akan muncul akun penjualan dan muncul akun harga pokok produksi.

Pencatatan yang dilakukan oleh UKM Dewi Prol Tape masih sangat sederhana. Pencatatan yang dilakukan adalah: catatan kas dan setara kas, catatan pembelian bahan baku dan bahan penolong, catatan produksi, catatan biaya operasional, catatan penjualan dan yang terakhir adalah catatan pajak penghasilan. Stice Dkk (2004) menyatakan tentang akuntansi berpasangan (double entry accounting) adalah sistem yang diterapkan secara umum dalam akuntansi. Dengan kata lain setiap percatatan harus selalu dicatat berpasangan sebagaimana yang sudah disebutkan dalam persamaan akuntansi. Sistem pencatatan yang dilakukan oleh UKM Dewi Prol Tape masih belum menggunakan sistem akuntansi berpasangan, sehingga pencatatan yang dilakukan belum menunjukkan saldo yang seimbang antar kredit dan debetnya.

Berdasarkan identifikasi transaksi yang sudah dilakukan oleh peneliti dapat disusun kode rekening dan daftar nama akun yang sesuai dengan UKM Dewi Prol Tape yang ditampilkan dalam tabel berikut: 
Tabel Kode Rekening dan Daftar Nama Akun

\begin{tabular}{|c|c|c|c|}
\hline Kode Akun & Nama Akun & Kode Akun & Nama Akun \\
\hline \multicolumn{2}{|l|}{ Aset Lancar } & \multicolumn{2}{|l|}{ Ekuitas } \\
\hline $110-10$ & Kas & $310-10$ & Modal \\
\hline $110-20$ & Bank & $310-20$ & Prive \\
\hline $120-10$ & Piutang Usaha & $320-10$ & Saldo Laba \\
\hline $120-20$ & Piutang Lain-Lain & \multicolumn{2}{|l|}{ Penjualan } \\
\hline $130-10$ & Persediaan Barang Jadi & $410-10$ & Penjualan \\
\hline $130-20$ & Persediaan Bahan Dalam Proses & $420-10$ & Retur Penjualan \\
\hline $130-30$ & Persediaan Barang Penolong & $430-10$ & Potongan Penjualan \\
\hline $130-40$ & Persediaan Bahan Baku & \multicolumn{2}{|l|}{ Beban } \\
\hline \multicolumn{2}{|l|}{ Aset Tetap } & $510-10$ & Harga Pokok Penjualan \\
\hline $160-20$ & Peralatan & $520-10$ & Biaya Bahan Baku \\
\hline $160-21$ & Akumulasi Penyusutan Peralatan & $520-20$ & Biaya Tenaga Kerja Langsung \\
\hline $160-30$ & Rumah & $520-30$ & Biaya Overhead Pabrik \\
\hline $160-31$ & Akumulasi Penyusutan Rumah & $520-31$ & Beban Transportasi \\
\hline $160-40$ & Oven & $520-32$ & Beban Air Pabrik \\
\hline $160-41$ & Akumulasi Penyusutan Oven & $520-33$ & Beban Listrik Pabrik \\
\hline $160-50$ & Kendaraan & $520-34$ & Beban Gas \\
\hline $160-51$ & Akumulasi Penyusutan Kendaraan & $610-10$ & Beban Gaji Penjualan \\
\hline $170-10$ & Aset Lain-Lain & $610-20$ & Beban Transportasi Penjualan \\
\hline \multicolumn{2}{|l|}{ Kewajiban } & $610-30$ & Beban Promosi \\
\hline $210-10$ & Hutang Usaha & $620-10$ & Beban Penyusutan Peralatan \\
\hline $210-20$ & Hutang Lain-Lain & $620-20$ & Beban Penyusutan Rumah \\
\hline \multirow[t]{3}{*}{$220-10$} & Hutang Bank & $620-30$ & Beban Penyusutan Oven \\
\hline & & $620-40$ & Beban Penyusutan Kendaraan \\
\hline & & $710-10$ & Pajak Penghasilan \\
\hline
\end{tabular}

Data Diolah Peneliti

Dengan kode rekening dan daftar nama akun yang telah dibuat, maka selanjutnya akan dimasukkan ke dalam Microsoft acces. Karena dalam penyusunan laporan keuangan untuk UKM Dewi Prol Tape yang akan digunakan adalah aplikasi Microsoft acces. Maka cara memasukkannya adalah dengan membuka aplikasi Microsoft acces lalu pilih createtabel dan 
buat field kode akun dan nama akun lalu masukkan rekomendasi kode rekening dan nama akun yang di atas, berikut adalah tampilannya dalam Microsoft acces:

Tabel Kode Rekening dan Daftar Nama Akun dalam Microsoft Acces

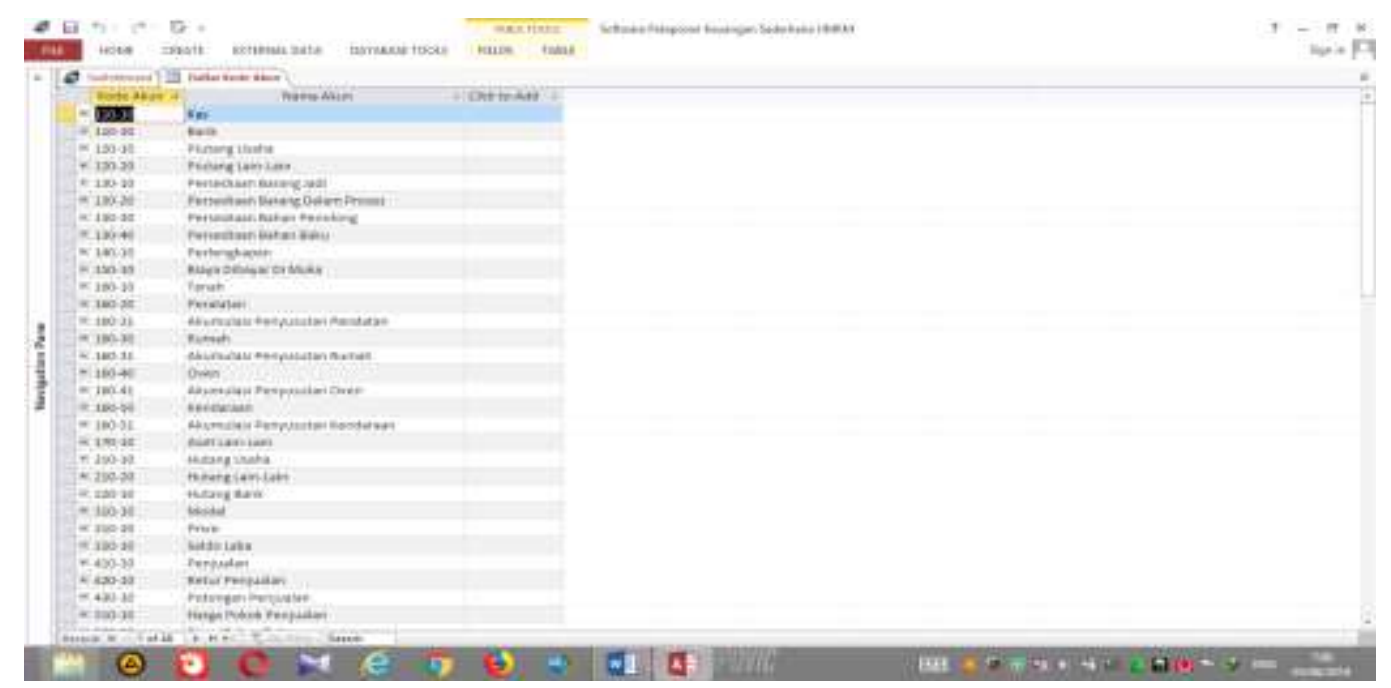

Rudianto (2012) menyatakan siklus akuntansi adalah rangkaian proses kegiatan yang dilakukan untuk menghasilkan satu informasi berupa laporan keuangan. Alur dari siklus akuntansi adalah sebagai berikut : Transaksi, Dokumen dasar, Jurnal, Buku Besar dan Laporan Keuangan. Transaksi pada UKM Dewi Prol Tape adalah berupa pembelian bahan baku, produksi dan penjualan. Dokumen dasar yang mereka miliki adalah berupa: catatan pembelian Bahan baku dan penggunaan bahan baku, catatan biaya tenaga kerja langsung dan overhead pabrik serta catatan penjualan. Jurnal atas transaksi yang terjadi pada UKM Dewi prol Tape pada Bulan Maret 2018 beserta tampilannya dalam Microsoft accesakan disajikan pada tabel berikut :

Tabel Jurnal Umum

UKM Dewi Prol Tape Maret 2018

\begin{tabular}{|c|c|c|c|c|}
\hline Tg1 & Nama Akun & & Debet & Kredit \\
\hline $1 / 3 / 18$ & $\begin{array}{l}\text { Kas } \\
\text { Bank }\end{array}$ & Modal & $\begin{array}{l}\text { Rp. } 5.000 .000 \\
\text { Rp. } 50.445 .921\end{array}$ & Rp. 55.445 .921 \\
\hline $1 / 3 / 18$ & $\begin{array}{l}\text { Peralatan } \\
\text { Oven } \\
\text { Kendaraan } \\
\text { Rumah }\end{array}$ & Modal & $\begin{array}{lr}\text { Rp. } & 1.059 .382 \\
\text { Rp. } & 2.188 .331 \\
\text { Rp } & 178.916 .666 \\
\text { Rp. } & 16.829 .100\end{array}$ & Rp 198.993.479 \\
\hline
\end{tabular}




\begin{tabular}{|c|c|c|c|}
\hline $1 / 3 / 18$ & $\begin{array}{l}\text { Persediaan Bahan Baku } \\
\text { Persediaan Bahan Penolong }\end{array}$ & $\begin{array}{l}\text { Rp } 1.807 .000 \\
\operatorname{Rp} 1.323 .000\end{array}$ & $\mathrm{Rp} \quad 3.130 .000$ \\
\hline $\begin{array}{c}31 / 3 / 1 \\
8\end{array}$ & $\begin{array}{l}\text { Persediaan Barang Dalam Proses } \\
\text { Persediaan Bahan Baku }\end{array}$ & Rp 1.688.390 & $\operatorname{Rp} 1.688 .390$ \\
\hline $\begin{array}{c}31 / 3 / 1 \\
8\end{array}$ & $\begin{array}{l}\text { Biaya Overhead Pabrik } \\
\qquad \text { Persediaan Bahan Penolong }\end{array}$ & $\operatorname{Rp} 1.196 .406$ & Rp 1.196.406 \\
\hline $\begin{array}{c}31 / 3 / 1 \\
8\end{array}$ & $\begin{array}{l}\text { Biaya Overhead Pabrik } \\
\text { Akumulasi Penyusutan Peralatan } \\
\text { Akumulasi Penyusutan Oven } \\
\text { Akumulasi Penyusutan Kendaraan } \\
\text { Akumulasi Penyusutan Rumah }\end{array}$ & Rp 293.434 & $\begin{array}{ll}R p & 25.517 \\
R p & 21.667 \\
R p & 118.750 \\
R p & 127.500\end{array}$ \\
\hline $\begin{array}{c}31 / 3 / 1 \\
8\end{array}$ & $\begin{array}{l}\text { Beban Listrik Pabrik } \\
\text { Beban Air Pabrik } \\
\text { Beban Gas } \\
\text { Beban Transportasi }\end{array}$ & $\begin{array}{l}\operatorname{Rp} 52.500 \\
\operatorname{Rp} 42.000 \\
\operatorname{Rp} 35.000 \\
\operatorname{Rp} 152.000\end{array}$ & $\operatorname{Rp} 281.500$ \\
\hline $\begin{array}{c}31 / 3 / 1 \\
8\end{array}$ & $\begin{array}{l}\text { Biaya Overhead Pabrik } \\
\qquad \begin{array}{l}\text { Beban Listrik Pabrik } \\
\text { Beban Air Pabrik } \\
\text { Beban Gas } \\
\text { Beban Transportasi }\end{array}\end{array}$ & $\operatorname{Rp} 281.500$ & $\begin{array}{lr}R p & 52.500 \\
R p & 42.000 \\
R p & 35.000 \\
R p & 152.000\end{array}$ \\
\hline $\begin{array}{c}31 / 3 / 1 \\
8\end{array}$ & $\begin{array}{l}\text { Persediaan Barang Dalam Proses } \\
\text { Biaya Tenaga Kerja Langsung }\end{array}$ & $\operatorname{Rp} 660.000$ & Rp 660.000 \\
\hline $\begin{array}{c}31 / 3 / 1 \\
8\end{array}$ & $\begin{array}{c}\text { Persediaan Barang Dalam Proses } \\
\text { Biaya Overhead Pabrik }\end{array}$ & Rp 1.771.340 & $\operatorname{Rp} 1.771 .340$ \\
\hline $\begin{array}{c}31 / 3 / 1 \\
8\end{array}$ & $\begin{array}{l}\text { Persediaan Barang Jadi } \\
\text { Persediaan Barang Dalam Proses }\end{array}$ & $\operatorname{Rp} 4.119 .730$ & $\operatorname{Rp} 4.119 .730$ \\
\hline $\begin{array}{c}31 / 3 / 1 \\
8\end{array}$ & Penjualan & $\begin{array}{l}\operatorname{Rp} 5.001 .000 \\
\operatorname{Rp} 6.116 .000\end{array}$ & Rp 11.117.000 \\
\hline & $\begin{array}{l}\text { Harga Pokok Penjualan } \\
\text { Persediaan Barang Jadi }\end{array}$ & $\operatorname{Rp} 4.119 .730$ & $\operatorname{Rp} 4.119 .730$ \\
\hline
\end{tabular}




\begin{tabular}{|c|c|c|c|}
\hline $\begin{array}{c}31 / 3 / 1 \\
8\end{array}$ & $\begin{array}{c}\text { Beban Promosi } \\
\text { Kas }\end{array}$ & $\operatorname{Rp} 50.000$ & Rp 50.000 \\
\hline $\begin{array}{c}31 / 3 / 1 \\
8\end{array}$ & Beban Gaji Penjualan & $\operatorname{Rp} 220.000$ & Rp 220.000 \\
\hline $\begin{array}{c}31 / 3 / 1 \\
8\end{array}$ & Pajak Penghasilan & $\operatorname{Rp} 111.170$ & Rp 111.170 \\
\hline $\begin{array}{c}31 / 3 / 1 \\
8\end{array}$ & $\begin{array}{l}\text { Beban Penyusutan Kendaraan } \\
\text { Akumulasi Penyusutan Kendaraan }\end{array}$ & $\operatorname{Rp} 672.917$ & Rp 672.917 \\
\hline & & Rp 284.812.515 & $\operatorname{Rp} 284.812 .515$ \\
\hline
\end{tabular}

Data Diolah Peneliti

\section{Tampilan Jurnal Umum dalam Microsoft Acces}

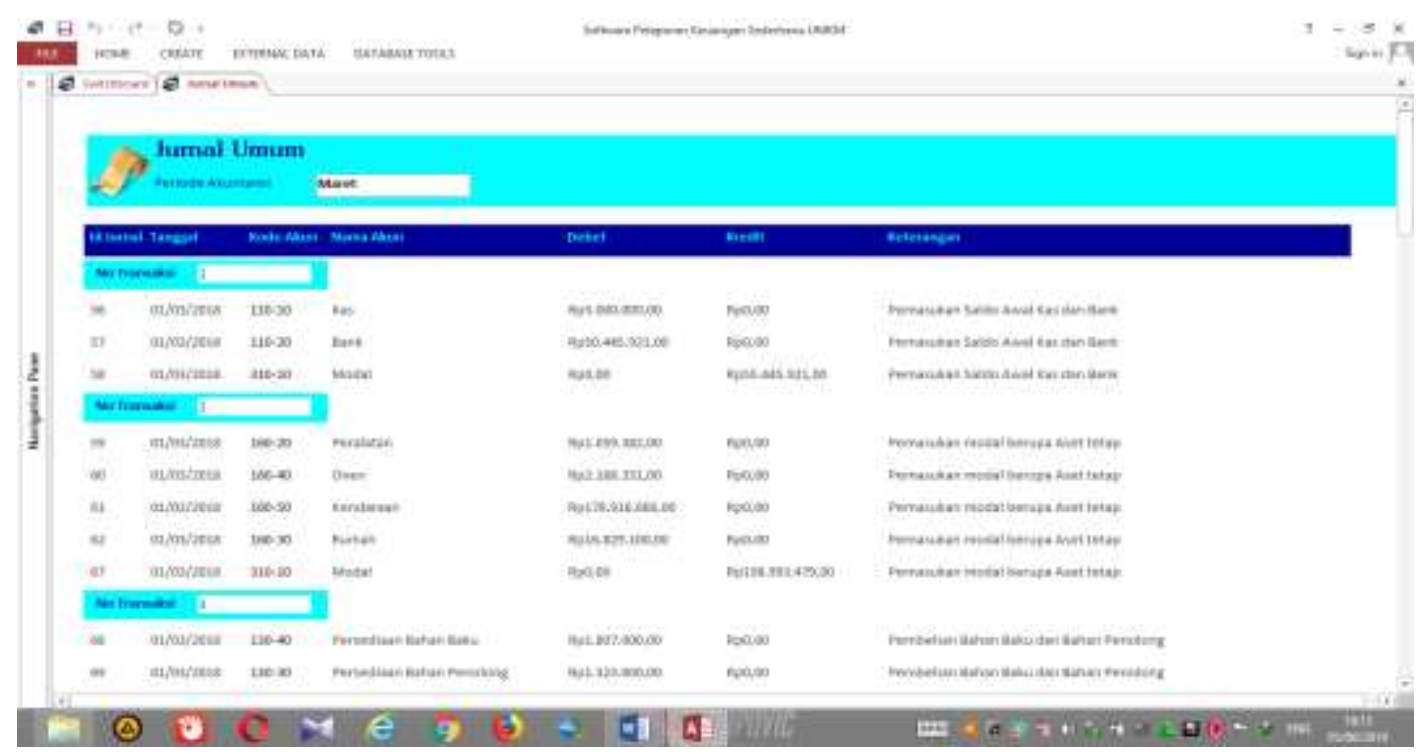

Selanjutnya setelah jurnal umum selesai dibuat adalah posting ke dalam buku besar, dimana dalam peneltian ini buku besar akan secara otomatis terbuat setelah input transaksi dalam jurnal dibuat, maka berikut adalah tampilan buku besar kas dalam Microsoft acces:

Tampilan Buku Besar dalam Microsoft Acces

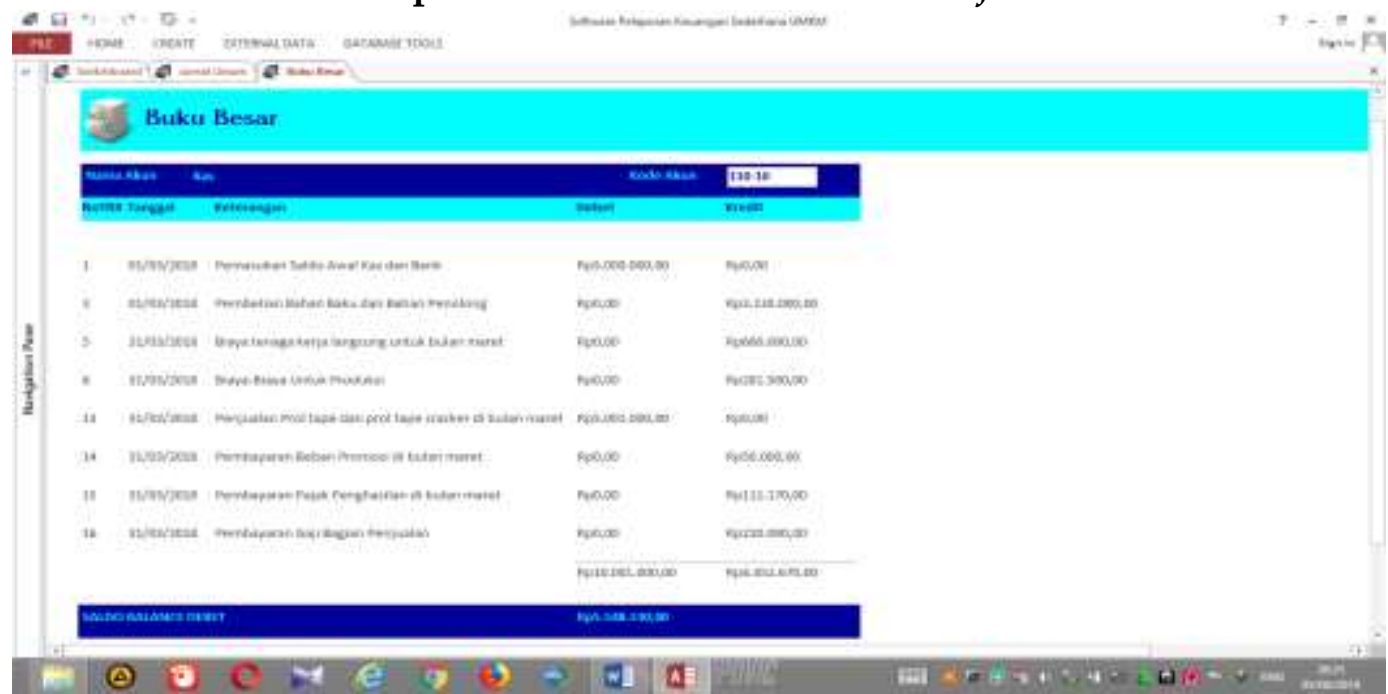


Buku besar dengan akun lainnya juga memiliki tampilan yang sama dengan buku besar kas. Setelah buku besar, maka selanjutnya siklus yang terakhir adalah laporan keuangan. Laporan keuangan yang dibuat untuk UKM Dewi Prol Tape terdiri dari empat unsur yaitu : laporan harga pokok produksi, laporan laba rugi, laporan posisi keuangan dan catatan atas laporan keuangan. Penyusunan laporan keuangan berbasis Microsoft acces berdasarkan SAK EMKM pada UKM Dewi Prol Tape dibuat dengan empat unsur tersebut, yang akan ditampilkan pada tabel berikut:

a) Laporan Harga Pokok Produksi

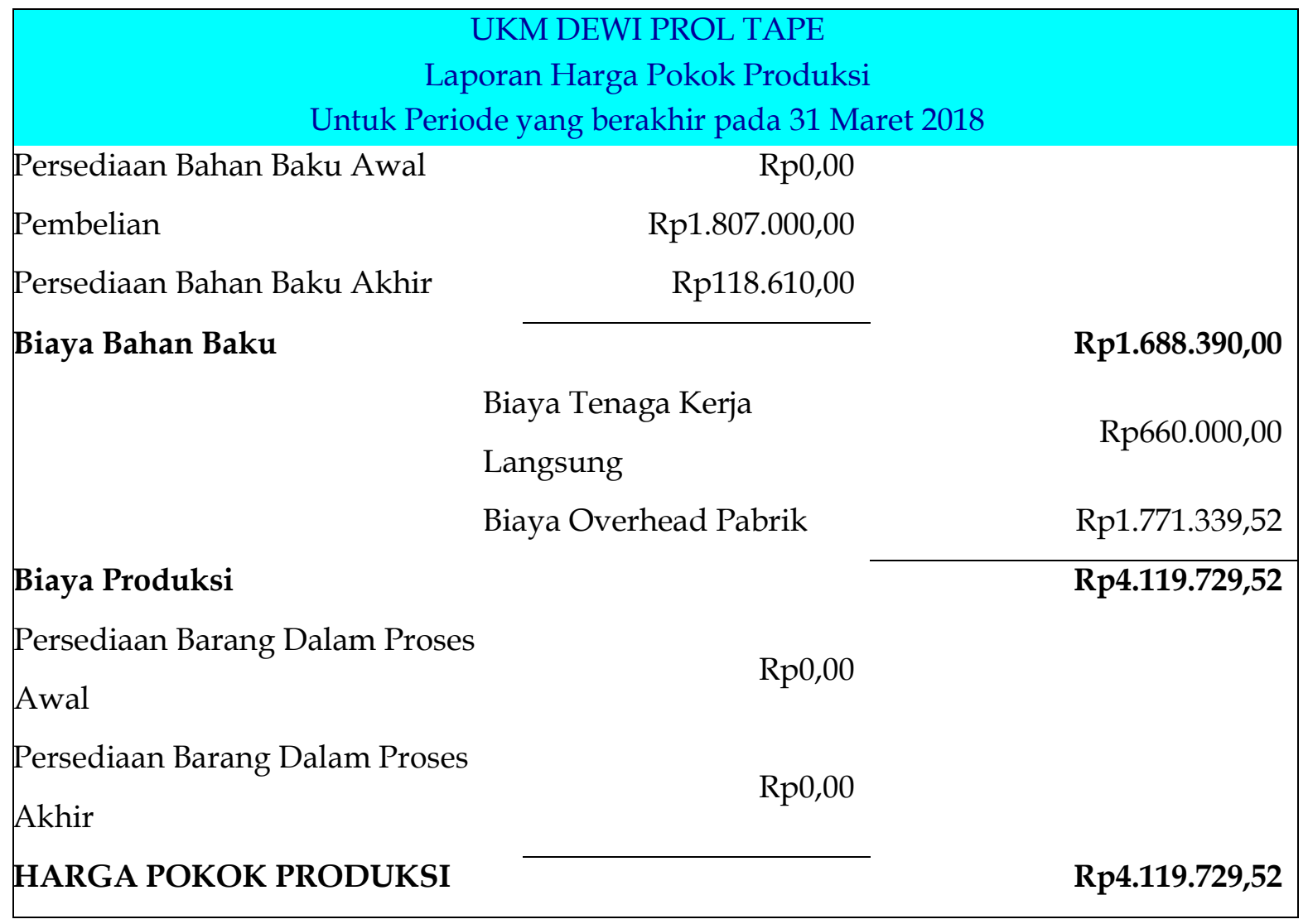

b) Laporan Laba Rugi

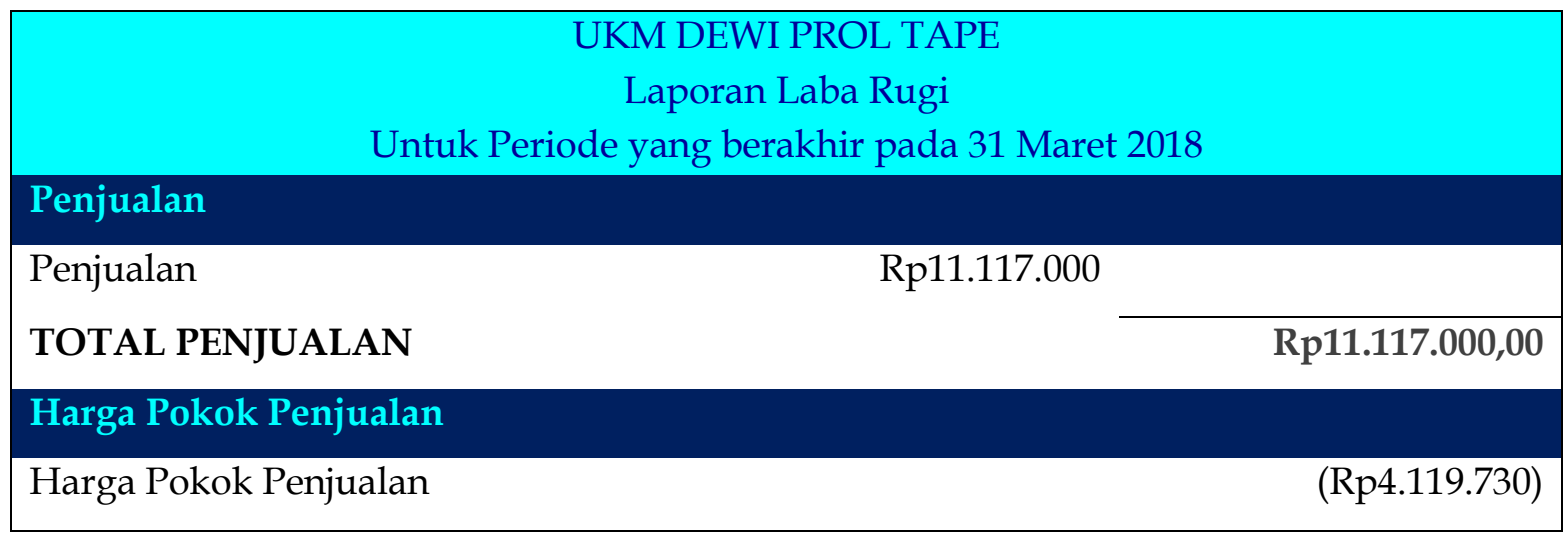




\begin{tabular}{lr}
\hline Beban Operasional & \\
\hline Beban Gaji Penjualan & $($ Rp220.000) \\
Beban Promosi & (Rp50.000) \\
Beban Penyusutan Kendaraan & (Rp672.917)
\end{tabular}

TOTAL BEBAN OPERASIONAL

(Rp942.917,00)

Pajak Penghasilan

Pajak Penghasilan

(Rp111.170)

Laba/Rugi Bersih Setelah Pajak

Rp5.943.183,48

c) Laporan Posisi Keuangan

\begin{tabular}{|c|c|}
\hline $\begin{array}{c}\text { UKM DEWI PROL TAPE } \\
\text { Laporan Posisi Keuangan } \\
\text { Per } 31 \text { Maret } 2018\end{array}$ & \\
\hline \multicolumn{2}{|l|}{ Aset Lancar } \\
\hline Kas & $\operatorname{Rp} 5.548 .330$ \\
\hline Bank & Rp 56.561.921 \\
\hline Persediaan Barang Jadi & $\operatorname{Rp} 0$ \\
\hline Persediaan Barang Dalam Proses & $\operatorname{Rp} 0$ \\
\hline Persediaan Bahan Penolong & $\operatorname{Rp} 126.594$ \\
\hline Persediaan Bahan Baku & Rp 118.610 \\
\hline TOTAL ASET LANCAR & Rp 62.355.455 \\
\hline \multicolumn{2}{|l|}{ Aset Tetap } \\
\hline Peralatan & Rp1.059.382 \\
\hline Akumulasi Penyusutan Peralatan & (Rp25.517) \\
\hline Rumah & Rp16.829.100 \\
\hline Akumulasi Penyusutan Rumah & (Rp127.500) \\
\hline Oven & Rp2.188.331 \\
\hline Akumulasi Penyusutan Oven & $(\mathrm{Rp} 21.667)$ \\
\hline Kendaraan & Rp178.916.666 \\
\hline Akumulasi Penyusutan Kendaraan & $(\mathrm{Rp} 791.667)$ \\
\hline TOTAL ASET TETAP & Rp198.027.128 \\
\hline TOTAL ASET & Rp260.382.583 \\
\hline \multicolumn{2}{|l|}{ Kewajiban } \\
\hline Hutang Usaha & $\mathrm{Rp} 0,00$ \\
\hline TOTAL KEWAJIBAN & Rp0,00 \\
\hline
\end{tabular}


d) Catatan Atas Laporan Keuangan

UKM DEWI PROL TAPE

Catatan Atas Laporan Keuangan

Per 31 Maret 2018

\section{UMUM}

Dewi Prol Tape didirikan di Malang pada tahun 2016, Usaha ini bergerak dalam bidang usaha manufaktur. Berdasarkan keputusan camat Kedungkandang Kota Malang Nomor: 188.451/94/35.73.03/2017 Usaha ini telah memenuhi kriteria sebagai entitas mikro, kecil dan menengah sesuai UU Nomor 20 Tahun 2008. Usaha ini berdomisili di Jalan Danau Paniai Dalam II C7/E5 Madyopuro dengan bentuk Usaha Perorangan.

\section{IKHTISAR KEBIJAKAN AKUNTANSI}

\section{a) Pernyataan Kepatuhan}

Laporan keuangan UKM Dewi Prol Tape belum sesuai dengan Standar Akuntansi Keuangan Entitas Mikro, Kecil dan Menengah.

\section{b) Dasar Penyusunan}

Dasar penyusunan laporan keuangan UKM Dewi Prol Tape adalah catatan kas, catatan pembelian bahan baku dan bahan penolong, catatan produksi, catatan penjualan, catatan gaji karyawan produksi dan catatan biaya operasional. Mata uang yang digunakan untuk penyusunan laporan keuangan adalah rupiah.

\section{c) Persediaan}

Biaya persediaan bahan baku meliputi biaya pembelian dan biaya angkut pembelian. Biaya konversi meliputi biaya tenaga kerja langsung dan overhead. Metode pencatatan yang dilakukan UKM Dewi Prol tape masih senderhana sehingga masih belum dapat mencerminkan nilai persediaan yang aktual.

\section{d) Aset Tetap}

Aset tetap milik UKM Dewi Prol Tape belum dicatat sebesar biaya perolehannya walaupun aset tersebut dimiliki secara hukum oleh entitas. UKM juga belum melakukan penyusutan atas aset tetapnya.

\section{e) Pengakuan Pendapatan dan Beban}

Pendapatan penjualan diakui ketika tagihan diterbitkan atau pengiriman produk 
dilakukan kepada pelanggan. Beban diakui saat terjadi.

\section{f) Pajak Penghasilan}

Pajak penghasilan telah mengikuti ketentuan perpajakan yang berlaku di Indonesia.

\section{Kas}

kas milik UKM Dewi Prol Tape dibagi menjadi dua yaitu tunai dan kas di bank yang rincian jumlahnya adalah sebagai berikut:

\section{Maret 2018}

Kas kecil Madyopuro - Rupiah

Rp 5.548.330

Kas di bank BRI - Rupiah

Rp 56.561.921

\section{Penjualan}

Penjualan dilakukan secra tunai dan dihasilkan dari penjualan prol tape dan prol tape cracker, yang rincian jumlahnya adalah sebagai berikut:

\section{Maret 2018}

Penjualan

$$
\operatorname{Rp} 11.117 .000
$$

\section{Beban pajak penghasilan}

Beban pajak penghasilan yang dibayarkan sebesar $1 \%$ dari omset bruto sesuai dengan PP no 46 tahun 2013, yang jumlahnya adalah sebesar:

\section{Maret 2018}

Pajak penghasilan $\quad$ Rp 111.170

Selanjutnya setelah rancangan penyusunan laporan keuangan berbasis Microsoft acces berdasarkan SAK EMKM dibuat, yang terakhir adalah peninjauan laporan keuangan UKM Dewi Prol Tape Berdasarkan SAK EMKM. Dimana pengakuan, pengukuran dan penyajian akun-akun dalam laporan posisi keuangan masih belum sepenuhnya sesuai dengan SAK EMKM. Sebagaimana pada akun-akun dalam laporan laba rugi yang juga masih belum sepenuhnya sesuai dengan SAK EMKM, karena pencatatan yang dilakukan masih sangat sederhana.

\section{PENUTUP}

\section{Kesimpulan}

Berdasarkan hasil penelitian dan pembahasan tentang rancangan penyusunan laporan keuangan berbasis Microsoft access berdasarkan SAK EMKM pada UKM Dewi Prol Tape, dapat diambil kesimpulan sebagai berikut: 
1) Laporan keuangan yang disusun oleh UKM Dewi Prol Tape meliputi catatan kas, catatan pembelian bahan, catatan produksi, catatan gaji karyawan dan catatan biayabiaya produksi. Hal ini masih belum sesuai dengan SAK EMKM yang disebutkan bahwa laporan keuangan UMKM minimal terdiri dari: laporan laba rugi, laporan posisi keuangan dan catatan atas laporan keuangan.

2) Rancangan penyusunan laporan keuangan dengan menggunakan Microsoft access dengan berdasarkan SAK EMKM yang dibuat untuk UKM Dewi Prol Tape adalah : laporan harga pokok produksi, laporan laba rugi, laporan posisi keuangan dan catatan atas laporan keuangan.

3) Dalam pengakuan, pengukuran dan penyajian laporan keuangan UKM Dewi Prol Tape masih sepenuhnya menerapkan SAK EMKM, karena dalam pencatatannya masih sangat sederhana.

4) Kendala yang dihadapi oleh Dewi Prol Tape dalam penyusunan laporan keuangan adalah sebagai berikut:

a) Kurangnya sumberdaya manusia yang ada untuk menyusun laporan keuangan.

b) Kurangnya pengetahuan UKM akan Standar Akuntansi Keuangan Entitas Mikro, Kecil dan Menengah, sehingga dalam penyusunannya masih belum sepenuhnya sesuai dengan standar.

\section{Saran}

Berdasarkan hasil analisa dan kesimpulan, maka peneliti memberikan saran dalam upaya penyusunan laporan keuangan berdasarkan SAK EMKM pada UKM Dewi Prol Tape sebagai berikut:

1. Bagi UKM

a) Dalam pembahasan telah disediakan rekomendasi pencatatan untuk menyusun laporan keuangan yang sesuai dengan SAK EMKM, sehingga rekomendasi dapat diterapkan dalam penyusunan laporan keuangan.

b) Peneliti sudah membuatkan rancangan penyusunan laporan keuangan dengan Microsoft access yang ditampilkan dalam lampiran, sehingga dengan rancangan tersebut dapat mempermudah UKM dalam penyusunannya.

c) Memahami dan mempelajari Standar Akuntansi Keuangan Entitas Mikro Kecil dan Menengah.

2. Bagi Peneliti Selanjutnya

a) Bagi peneliti selanjutnya diharapkan dapat menemukan objek yang berbeda bentuk kegiatan usahanya dari penelitian ini, sehingga dapat merekomendasikan rancangan 
penyusunan laporan keuangan dengan Microsoft access berdasarkan SAK EMKM yang dapat digunakan oleh UKM yang lain.

b) Dapat memperbaiki kekurangan dan kelemahan penelitian ini, dimana UKM yang digunakan dalam penelitian ini masih berskala mikro, sehingga penelitian yang selanjutnya diharapkan untuk dapat mencari UKM yang berskala kecil atau menengah agar penelitian yang dilakukan dapat menjadi lebih baik dari yang sudah dilakukan sekarang.

\section{DAFTAR PUSTAKA}

Audriene, Dinda. (23 Maret 2017). OJK Putar Otak Demi Target Muluk IPO 1.500 UMKM di 2022. CNN Indonesia. Diperoleh tanggal 27 Februari 2018 dari https://m.cnnindonesia.com/ekonomi/20170323133414-78-202250/ojk-putar-otakdemi-target-muluk-ipo-1500-umkm-di-2022

CFISEI., HIPMI., BPUI. (2009). Alternatif Pembiayaan Terhadap UMKM Melalui Pasar Modal di Indonesia. Jakarta Selatan: PT. Telaga Ilmu.

Departemen Pengembangan UMKM-Bank Indonesia. (2016). Laporan Perkembangan Kredit UMKM Triwulan 2016. Jakarta. Diperoleh tanggal 26 Februari 2018 dari http://www.bi.go.id/id/umkm/kredit/laporan/pages/Laporan-Perkembangankredit-UMKM-Triwulan-II-2016.aspx

Ikatan Akuntan Indonesia. (2016). Standar Akuntansi Keuangan Entitas Mikro, Kecil, dan Menengah Per 2018. Jakarta: Graha Akuntan.

Ikatan Akuntan Indonesia. (2018). Standar Akuntansi Keuangan Entitas Tanpa Akuntabilitas Publik cetakan keenam. Jakarta: Graha Akuntan.

Primus, Josephus. (3 Oktober 2015). Indonesia dan India Makin penting bagi Pasar Inovasi dan Teknologi. Kompas.com. Diperoleh tanggal 6 Maret 2018 dari https://ekonomi.kompas.com/read/2015/10/03/185353026/Indonesia.dan.India.M akin.Pentng.bagi.Pasar.Inovasi.Teknologi

Raja, Oskar., Jalu, Ferdi., Dral, Vincent. (2010). Kiat Sukses Mendirikan \& Mengelola UMKM. Jakarta: LA Press.

Rudianto. (2012). Pengantar Akuntansi Konsep dan Teknik Penyusunan Laporan Keuangan Adaptasi IFRS. Jakarta: Erlangga.

Sadeli, Muhammad. (2011). 7 Jam Belajar Interaktif Acces 2010 Untuk Orang Awam. Palembang: Maxikom.

Stice, Earl K., Stice, James D., Skousen, K. Fred. (2004). Intermediate Accounting Auntansi Intermediate Edisi Lima Belas. Jakarta: Sakemba Empat.

www.depkop.go.id, diakses 24 Februari 2018, dari http://www.depkop.go.id/beritainformasi/data-informasi/data-umkm/ 